\title{
A representação das mulheres no rap: instituindo espacialidades, quebrando barreiras
}

\section{The representation of women in rap: instituting spacialities, breaking barriers}

\author{
Ana Carolina dos Santos Marques ${ }^{1 *} \varangle$ (iD, Ricardo Lopes Fonseca ${ }^{2} \varangle$ (iD \\ 1Departamento de Geografia, Faculdade de Ciências e Tecnologia, Universidade Estadual \\ Paulista "Júlio de Mesquita Filho", Presidente Prudente, São Paulo, Brasil \\ 2 Departamento de Geociências, Universidade Estadual de Londrina, Londrina, Paraná, Brasil \\ E-mail: ricardolopesfonseca@hotmail.com \\ *E-mail para correspondência: anaaa0@hotmail.com
}

Recebido (Received): 15/05/2019

Aceito (Accepted):23/04/2020

\begin{abstract}
Resumo: O gênero evidencia-se como um fator determinante na vida das mulheres. De acordo com as estruturas sociais, elas são obrigadas a vivenciar situações marcadas pela discriminação de gênero, opressão, machismo e misoginia. As mulheres constroem o espaço geográfico de forma diferenciada dos outros grupos sociais, lutando cotidianamente contra a exclusão sócio-espacial, a favor da equidade, de sua afirmação e de seu direito a ocupar diferentes âmbitos da sociedade. Neste sentido, a temática da pesquisa se relaciona à Geografia por meio da questão da espacialidade que as mulheres ocupam ou deveriam ocupar, principalmente por meio do Hip Hop e de seu elemento rap, uma vez que atribuem visibilidade às populações vulneráveis e se evidenciam como potenciais ferramentas para auxiliar as mulheres na reivindicação de seus direitos e denúncia das desigualdades. Por meio deste artigo, objetiva-se investigar como a mulher é retratada nos raps masculinos e femininos a fim de compreender se existem diferenças nas formas de representação e quais os desdobramentos que esse cenário pode provocar nas espacialidades instituídas. Para tanto, 20 raps 10 cantados por homens e 10 por mulheres - foram analisados por meio da Análise de Conteúdo de Bardin (1977) que possibilitou compreender se as mulheres estão ocupando espaços no Hip Hop e no rap, quais as relações sociais e de poder que estão sendo estabelecidas e em que medida os elementos contribuem para sua afirmação. A primeira parte do artigo discute a temática de gênero, do feminismo, das Geografias Feministas e do Hip Hop, a segunda parte contém os materiais e métodos utilizados na pesquisa e a terceira parte apresenta os resultados obtidos.
\end{abstract}

Palavras-chave: Gênero; Hip Hop; Geografias Feministas.

Abstract: Gender is seen as a determining factor in women's lives. Acoording to social structures, they are forced to experience situations that are marked by gender discrimination, opression, machismo and misogyny. The women construct the geographic space differently from other social groups, struggling daily against socio-spatial exclusion, in favor of equity, its affirmation and its right to occupy different spheres of society. In this sense, the research theme is related to Geography through the issue of spatiality that women occupy or should occupy, mainly through Hip Hip and its rap elemento, since they atribute visibility to vulnerable populations and are evidenced as potential tools to assist women in the claim rights and denunciation of inequalities. Through this article, the objective is to investigate how the women are portrayed in male and female raps in order to understand if there are differences in the representation and what developments this scenario can cause in the instituted spatialities. To that end, 20 raps -10 sung by men and 10 by women - were analyzed through Bardin's Content Analysis (1977) that made it possible to understand if women are occupying spaces in Hip Hop and rap, what social relations and power that is being established and to what extent the elements contribute to its affirmation. The first part of the article discusses the theme of gender, feminism, Feminist Geography and Hip Hop, the second part contains the materials and methods used in the research and the third part presents the results obtained.

Keywords: Gender; Hip Hop; Feminist Geography. 


\section{Introdução}

O gênero é um fator determinante na vida das mulheres, com base nele, as estruturas sociais impõem a elas um contexto social e espacial permeado por disparidades, opressão, machismo, discriminação, estigmas, misoginia, medo e violência, por exemplo. "Ninguém nasce mulher: torna-se mulher" (BEAUVOIR, 1967, p. 9), a icônica frase de Beauvoir define bem as discussões de gênero. Gênero é uma construção social em que o homem e a mulher são moldados pelos sistemas sociais correspondentes ao contexto em que vivem, uma divisão é imposta socialmente e as(os) obriga a seguir uma serie de comportamentos preestabelecidos (RUBIN, 2017). Deste modo, ninguém nasce mulher, torna-se mulher à medida que desde criança a mulher é ensinada a cuidar da casa, cuidar dos irmãos e em datas especiais ganhar presentes como utensílios infantis de cozinha, bonecas, carrinhos de bebê e ferros de passar, por exemplo. Quando faz algo que foge das convenções do que é ser mulher, é repreendida e reprimida.

Beauvoir (1970) aponta que a mulher é historicamente o Outro, ela nunca partilhou o mundo em igualdade de condições com o homem, esse mundo foi criado pelos homens ou, pelo menos, foram eles que levaram o crédito pela grande maioria das conquistas. As mulheres foram obrigadas a serem complacentes com essa estrutura social, marcada pelo machismo e pelo patriarcalismo.

Os dados brasileiros a respeito das desigualdades de gênero evidenciam a necessidade da luta contra a discrepância entre homens e mulheres e a emergência do protagonismo feminino. De acordo com as Estatísticas de Gênero do Instituto Brasileiro de Geografia e Estatística (IBGE), de 2018, apesar das mulheres possuírem mais anos de estudo do que os homens, elas ainda ganham remuneração menor, os homens ganham em média $\mathrm{R} \$ 2.306,00$ e as mulheres $\mathrm{R} \$ 1.764,00$. Em 2017, apenas 10,5\% dos assentos da Câmara dos Deputados eram ocupados por mulheres e, no mundo as mulheres ocupavam 23,6\% dos assentos. Em 2016, 37,8\% dos cargos gerenciais eram de mulheres. Em relação ao tempo dedicado com cuidado de pessoas e/ou afazeres domésticos, em 2016 os homens gastavam em média 10,5 horas semanais enquanto as mulheres gastavam 18,1 horas semanais, cerca de $73 \%$ a mais que eles (IBGE, 2018).

Esse cenário marcado por assimetrias aponta para a necessidade de que as mulheres assumam maior protagonismo nos diversos âmbitos da sociedade e lutem por condições de equidade em relação aos homens. Neste sentido, o movimento feminista se apresenta como um grande mecanismo de reivindicação do protagonismo feminino. Adichie (2014) acredita que feminista é o homem ou a mulher que reconhece que há um problema de gênero e que é necessário resolvê-lo. A autora define: "Feminista: uma pessoa que acredita na igualdade social, política e econômica entre os sexos" (ADICHIE, 2014, p. 40) e aponta para a necessidade da construção de uma sociedade mais justa:

Perdemos muito tempo ensinando as meninas a se preocupar com o que os meninos pensam delas. Mas o oposto não acontece. Não ensinamos meninos a se preocupar em ser "benquistos". Se, por um lado, perdemos muito tempo dizendo às meninas que elas não podem sentir raiva ou ser agressivas ou duras, por outro, elogiamos ou perdoamos meninos pelas mesmas razões [...] A questão de gênero é importante em qualquer canto do mundo. É importante que comecemos a planejar e sonhar um mundo diferente. Um mundo mais justo. Um mundo de homens mais felizes e mulheres mais felizes, mais autênticos consigo mesmos. E é assim que devemos começar: precisamos criar nossos filhos de uma maneira diferente (ADICHIE, 2014, p. 19-21).

Como destaca Adichie (2014), as mulheres são ensinadas a agradar os homens e a levar em conta o que eles pensam delas, porém, o inverso não acontece, apontando a construção de uma masculinidade dominante, que acentua as diferenças de gênero e coloca o homem em uma posição superioridade. Desta forma, o movimento feminista potencializa o entendimento das relações sociais marcadas pelo gênero e, consequentemente, pelas discrepâncias.

Considerando ser fundamental a ação de se situar na pesquisa os autores deste artigo adotaram uma posição direcionada ao feminista negra, bem como, acreditam que a interseccionalidade é essencial. O conceito de interseccionalidade é criado por Crenshaw (2004) em que se defende a imprescindibilidade de considerar as sobreposições entre as questões de gênero, raça e classe social, possibilidade a compreensão de "[...] como essas discriminações operam juntas, limitando a chances de sucesso das mulheres negras" (CRENSHAW, 2004, p. 8).

Carneiro (2003a) discute a necessidade de o feminismo politizar as desigualdades de gênero e considerar as especificidades de cada grupo, transformando as mulheres em novos sujeitos políticos que assumem os lugares que ocupam. Neste contexto cria-se o Feminismo Negro que "[...] tem como principal eixo articulador o racismo e seu impacto sobre as relações de gênero, uma vez que ele determina a própria hierarquia de gênero em nossas sociedades" (CARNEIRO, 2003b, p. 51). O feminismo negro é uma forma de luta e resistência que discute não só as desigualdades de gênero, mas também as implicações que o 
racismo e as discrepâncias sociais possuem no aprofundamento das relações dissimétricas, que aumentam e consolidam a exclusão socioeconômica das mulheres negras. É importante destacar que esse movimento não luta apenas pelas mulheres negras, mas sim pela mudança na estrutura social, abrangendo desde as mulheres brancas aos grupos LGBTQIA+ (lésbicas, gays, bissexuais, transexuais/transgêneros/travestis, queer, intersexuais e assexuais).

Considerando as diferenças de gênero e os desdobramentos que esta categoria causa na vida das mulheres, é fundamental a elaboração de pesquisas que investiguem a temática, as ciências humanas são áreas que possuem diversas contribuições nos estudos. A Geografia, por exemplo, apresenta potencialidades que possibilitam pesquisas a respeito da organização do espaço geográfico enquanto produto das relações de gênero e também raciais que fazem com que as mulheres possuam determinadas espacialidades, mobilidades e territórios devido aos condicionantes sociais que as influenciam.

Os estudos de gênero foram por muito tempo negligenciados na Geografia. Monk e Hanson (2016) apontam que apesar do feminismo ser uns dos maiores responsáveis por instigar uma transformação na atual sociedade marcada pelas desigualdades e merecer atenção nos estudos, as pesquisas geográficas não atribuíram grande atenção às questões relacionadas às mulheres.

De acordo com Silva (2009a) aponta que o projeto feminista da Geografia é ambicioso, porque vai além da complexidade teórica, possuindo um compromisso político com a transformação das estruturas de poder criadoras das assimetrias de gênero, que atribuem às mulheres um status social inferior ao dos homens. É fundamental destacar, como ressalta Silva (2009b), que as Geografias Feministas são influenciadas pelas teorias pós-coloniais, pós-estruturalistas e psicanalistas e não estudam apenas as mulheres como categoria universal, as negras e indígenas também são contempladas e há ainda os estudos LGBTQIA+. Essas abordagens múltiplas fazem com que a nomenclatura Geografia feminista, seja substituída por Geografias feministas para representar a pluralidade científica e ideológica.

Monk e Hanson (2016) debatem que a Geografia, em sua maior parte, ignora os problemas femininos e isso pode ser explicado por razões como: o conhecimento é um construto social e a Geografia foi formada nos moldes positivistas e por homens, predominando assim, a visão masculina nos estudos; mesmo com o positivismo lógico tendo perdido força e o marxismo ganhar destaque defendendo a transformação social, pouco se preocuparam em abordar as mulheres; ao longo de seu desenvolvimento a Geografia reforçou o sexismo consolidando a inadequada especificação dos problemas pesquisados, a cegueira de gênero que ignora esse elemento nas pesquisas, a presunção dos papéis de gênero tradicionais e a negação da significância do gênero e das atividades empreendidas por mulheres. Segundo as autoras, os estudos geográficos relacionados às mulheres são essenciais para se compreender a sociedade, uma vez que elas constroem e modificam o espaço geográfico e suas espacialidades são distintas das espacialidades dos homens. Portanto, a Geografia possibilita compreender onde estão as mulheres, quem são e qual seu papel na produção do espaço, os fenômenos vivenciados por elas - segregação sócio-espacial e territorialidades, por exemplo -, além de contribuir no encontro de caminhos que possam tornar a produção do espaço mais justa, baseada na equidade.

O Hip Hop é uma cultura que ilustra as intersecções entre gênero, raça, classe social e espaço. Ele se evidencia enquanto uma cultura marginal, praticada em sua maioria por pessoas negras e das camadas populares, representando uma forma de lazer e práxis política para esse público. Deste modo, possui contribuições para a luta das mulheres por equidade, possibilitando seu autorreconhecimento e autoafirmação por meio da fala, afirmação da identidade e da denúncia das injustiças que vivenciam. De acordo com Machado (2012), o Hip Hop foi criado nos guetos de Nova Iorque entre os anos de 1960 e 1970, como forma de denúncia à ausência de direitos básicos que a população residente passava e de reivindicação para a melhoria dessa situação. No Brasil, ele ganhou força na década de 1980 por meio dos bailes blacks realizados no Rio de Janeiro e em São Paulo e proporcionou às classes menos favorecidas - em sua maioria negras(os) - terem maior visibilidade, se afirmarem enquanto negras(os) e resistirem às desigualdades socioeconômicas e à exclusão social se expressando por meio da música, dança e pintura (MACHADO, 2012).

O movimento possui cinco elementos: grafite, danças urbanas, consciência e o MC e o DJ que resultam no rap. O rap representa a música e por meio dos conteúdos das letras possibilita a afirmação política, denunciando contextos marcados por distinções socioeconômicas, de gênero e raciais, segregação urbana e o direito à cidade. Ele expressa a identidade da população com seu lugar, a disputa pela manutenção de seus espaços, a valorização da periferia e a denúncia das injustiças e da má gestão que segregam espacialmente as populações mais vulneráveis, destinando-as locais desprovidos de infraestrutura básica. Os grupos se 
apropriam do seu espaço - a periferia -, mesmo com suas carências e o transformam em um local de resistência, ação política, cultura e educação, criando uma identidade.

As(os) rappers também se apropriam dos espaços públicos e disseminam sua cultura para outras pessoas. Deste modo, o Hip Hop possibilita que jovens da periferia - majoritariamente, negras(os) - instituam espacialidades na cidade por meio de suas manifestações culturais. Os pesquisadores optaram pelo conceito de espaço nesta pesquisa, por acreditar que ele possibilita a compreensão das relações de gênero, raça e classe. Massey (2008) estabelece três proposições para definir espaço. Primeiro, ele é produto de interrelações que são construídas por meio de intersecções, desde a imensidão do global até o intimamente pequeno. Segundo, ele é esfera da possibilidade da existência da multiplicidade, em que distintas trajetórias coexistem. E terceiro, ele está sempre em construção. Assim, o espaço reflete as relações sociais, políticas, econômicas e culturais que nele se materializam e à medida que mulheres se façam presentes nos diversos âmbitos da sociedade, estão ocupando espaços e imprimindo suas marcas no mesmo. Conforme mais mulheres estejam presentes no Hip Hop e no rap, mais espaço elas estarão conquistando, se reafirmando e politizando a cultura para as questões que consideram pertinentes.

Com todas as potencialidades que o rap apresenta, o elemento se evidencia como uma importante ferramenta que pode ser utilizada pelas mulheres para a luta contra as desigualdades de gênero. Como outros locais e movimentos, o rap ainda apresenta discursos machistas que precisam ser desconstruídos e letras múltiplas em relação às mulheres, de acordo com Matsunaga (2008) as letras femininas e masculinas possuem sentidos diferentes. Nas letras masculinas, a mulher ocupa papel de mãe e namorada sendo valorizada por ser negra e batalhadora, mas condenada por ser vulgar e um objeto, a ela são destinados os espaços privados, como a casa. Já nas letras femininas, são relatadas as experiências pessoais das mulheres, o preconceito sofrido e oposição aos estereótipos, destinando-lhes os espaços públicos. Apesar da predominância dos homens no rap e dos estereótipos que muitas vezes são afirmados por eles, a participação das mulheres tem crescido e elas estão realizando suas contestações, principalmente em relação ao sexismo.

Desta forma, a temática do Hip Hop e do rap tem importância para a Geografia à medida que se materializam espacialmente e alteram o arranjo espacial. O movimento contribui para a afirmação da população negra e de sua cultura, imprimindo suas marcas no espaço geográfico e denunciando as diferenças socioeconômicas, o racismo e a segregação sócio-espacial. Além disso, é relevante que a Geografia investigue a presença das mulheres no Hip Hop e no rap, uma vez que essas são ferramentas que podem auxiliar em sua luta por equidade, se torna fundamental compreender de que forma as mulheres estão presentes, se estão ocupando espaços e de que forma a participação no movimento influencia em suas trajetórias de vida e na instituição de espacialidades.

Tendo em vista a necessidade da presença das mulheres no rap, o artigo objetiva investigar como a mulher é retratada nos raps masculinos e femininos a fim de compreender se existem diferenças nas formas que são representadas, se elas estão ocupando espaço no elemento e em que medida isso tem contribuído para sua afirmação e instituição de suas espacialidades.

\section{Materiais e métodos}

$\mathrm{O}$ artigo apresenta uma análise de letras de rap produzidas por homens e por mulheres a fim de compreender como a mulher é retratada pelos dois gêneros no rap. Para tanto, a técnica utilizada foi a Análise de Conteúdo de Bardin (1977), que permite a(ao) pesquisadora(or) uma leitura e interpretação aprofundada dos significados que as(os) atrizes(atores) sociais atribuem à realidade a partir de categorizações:

[...] pode, teoricamente, apoiar-se ou reportar-se aos elementos básicos do mecanismo clássico da comunicação: a mensagem (significação e código) e seu suporte ou canal, de uma parte; o emissor e receptor, de outra parte, como polos de inferência (comuns) propriamente ditos. (BARDIN, 1977, p. 169, tradução nossa).

De acordo com Fonseca (2015), a Análise de Conteúdo de Bardin é realizada em três etapas essenciais: pré-análise, exploração do material e tratamento dos resultados. Na primeira etapa há a ordenação dos materiais, na segunda ocorre o resumo dos materiais e exploração do referencial teórico e por fim, na terceira etapa acontece a interpretação e análise dos resultados.

Para a categorização das letras de rap foi utilizado o modelo elaborado por Fonseca (2015) e baseado na Análise de Conteúdo de Bardin (1977), conforme a Tabela 1. O modelo de análise da Tabela 1 possui uma descrição da categoria identificada, as unidades de registro (UR) correspondem ao tema em comum que os exemplos de verbalizações tratam, os exemplos de verbalizações referem-se a determinadas palavras 
identificadas nas letras de rap que se enquadram na unidade de registro, a frequência relativa revela o percentual da presença dos exemplos de verbalizações nas letras e no metatexto é apresentada a análise dos campos da tabela.

Tabela 1: Letras de rap selecionadas para a análise

\begin{tabular}{|c|c|c|}
\hline \multicolumn{3}{|l|}{ Categoria: Nome da Categoria } \\
\hline \multicolumn{3}{|l|}{ Descrição da Categoria. } \\
\hline Unidades de Registro & Exemplos de Verbalizações & Frequência Relativa \\
\hline UR1 - Nome da UR & Palavras relacionadas à unidade. & $\begin{array}{c}\text { \% de incidência em relação ao } \\
\text { universo da categoria. }\end{array}$ \\
\hline UR2 - Nome da UR & Palavras relacionadas à unidade. & $\begin{array}{c}\text { \% de incidência em relação ao } \\
\text { universo da categoria. }\end{array}$ \\
\hline \multicolumn{3}{|c|}{$\begin{array}{c}\text { Metatexto } \\
\text { Discorrer acerca da análise }\end{array}$} \\
\hline
\end{tabular}

Fonte: Fonseca, 2015.

No total 20 letras de rap foram selecionadas, sendo 10 cantadas por homens e 10 por mulheres, na Tabela 2 é possível visualizar as músicas escolhias, assim como seu ano de lançamento. A seleção - realizada em 2018 - ocorreu por meio de uma busca simples no site Google com a seguinte frase: "raps que falam de mulheres". Os resultados da busca foram diversos, as letras encontradas foram lidas para conferir se realmente tratavam do tema e as $20 \mathrm{com}$ maior incidência foram utilizadas nesta pesquisa. Considerando que as músicas selecionadas são de homens e de mulheres, estes dois gêneros foram utilizados como unidades de registro a fim de explicitar a diferença na abordagem da mulher nos raps.

Tabela 2: Letras de rap selecionadas para a análise

\begin{tabular}{cc}
\hline Raps Cantados por Mulheres & Raps Cantados por Homens \\
\hline Quebra do status quo - Issa Paz (2015) & Mulher elétrica - Racionais Mcs (2008) \\
Matriarca - Omnira (2017) & Loraburra - Gabriel o pensador (1993) \\
Não não não - Odisséia das Flores (2017) & Mulheres vulgares - Racionais MC's (1990) \\
Rap plus size (part. Sara Donato) - Issa Paz (2016) & A pecadora - Nego do rap (2008) \\
Menina pretinha - Mc Soffia (2016) & Jack - Nocivo Shomon (2018) \\
Delete nos machista - Dory de Oliveira (2016) & Rap news - MC Sid (2017) \\
Poetisas no topo - Pineapple (2017) & Imagem feminina - Terrorista Verbal (2015) \\
Ela encanta - Mariana Peralta (2016) & Estilo cachorro - Racionais MC's (2002) \\
Preta de quebrada - Flora Matos (2017) & Não é pra puta - Patrick Horla (2016) \\
Negra tinta - Bia Ferreira (2018) & Raiva - Shawlin (2015) \\
\hline
\end{tabular}

Org.: os autores, 2019.

As letras de rap foram agrupadas em três categorias, resultando consequentemente em três tabelas de análise: empoderamento feminino; denúncia das desigualdades de gênero; e estigmatização da mulher. Estas categorias foram estabelecidas após uma análise prévia das letras, identificação das verbalizações relacionadas as mulheres e agrupamento destas em temas gerais (categorias). Além disso, foram consideradas as orientações de Salvi (2009):

A primeira regra de categorização é baseada no preceito de que categorias necessitam ser válidas, pertinentes ou adequadas aos objetivos da análise, à natureza do material que está sendo estudado e às questões a que se pretende responder com a pesquisa. [...]. A segunda regra básica é a da exaustividade. As categorizações deverão ser exaustivas no sentido de poderem enquadrar todo o conteúdo. [...]. A terceira regra geral da categorização é a da homogeneidade, ou seja, a sua organização deve ser fundamentada em um único princípio ou critério de classificação. [...] significa poder afirmar que todo o conjunto é estruturado em uma única dimensão de análise, numa única variável. [...]. A quarta regra da categorização é a da exclusão mútua. O pesquisador precisa assegurar que cada elemento possa ser classificado exclusivamente em apenas uma categoria. [...]. A quinta regra da categorização é a da objetividade, consistência ou fidedignidade, estreitamente relacionada ao critério de exclusividade (SALVI, 2009, p. 175-176).

Nas tabelas de análise foram estabelecidas duas unidades de registro - mulheres e homens - a fim de explicitar a forma como ambos tratam das categorias em seus raps, possibilitando investigar se há diferença no modo como a temática geral das mulheres é abordada pelos dois gêneros. Além disso, foi procurado nas letras, palavras que se referiam as mulheres, as mesmas são apresentadas nos exemplos de verbalizações e a 
frequência relativa com que apareciam foi contabilizada para construção das tabelas. A frequência absoluta das verbalizações é apresentada após as tabelas de categorização.

\section{Resultados e discussões: a representatividade das mulheres no rap}

As mulheres ocupam uma posição desigual em relação aos homens nos diversos âmbitos da sociedade e isso se torna ainda mais evidente quando se analisa as mulheres negras que são vítimas da intersecção entre raça, gênero e classe social caracterizando-as como mais vulnerável socialmente. Uma vez que o Hip Hop e seu elemento rap são manifestações culturais importantes para que as populações vulneráveis possam reivindicar seus direitos e conquistar visibilidade considerável no cenário nacional, a presença das mulheres é importante, assim como a forma pela qual elas são representadas nos raps.

As Tabelas 3, 4 e 5 apresentam os resultados dessa análise. A Tabela 3 destaca como as mulheres são retratadas nos raps com verbalizações relacionadas ao empoderamento feminino. As verbalizações demonstram que as(os) músicas(os) reconhecem a importância das mulheres assumirem posições de protagonismo e se unirem contra qualquer tipo de discriminação. Ainda que com frequência muito inferior à das rappers, muitos rappers também incentivam a afirmação feminina, fato relevante, uma vez que a empatia dos outros grupos e o incentivo à luta alheia são importantes para o fortalecimento deste movimento de reivindicação de direitos.

Tabela 3: Empoderamento feminino

Categoria: Empoderamento feminino

Empoderar é antes de mais nada, pensar em caminhos de reconstrução das bases sociopolíticas, rompendo com o que está posto, ou seja, é um instrumento de emancipação política e social. Embora possa contar com estímulos externos, é uma movimentação interna de tomada de consciência ou do despertar de diversas potencialidades que definirão estratégias de enfrentamento das práticas do sistema de dominação machista, misógino e racista. O empoderamento individual resulta no empoderamento coletivo por meio da junção de indivíduos que se constroem e reconstroem continuamente. Empoderar significa se autoafirmar, autorreconhecer, autovalorizar, autoconhecer (BERTH, 2018).

A palavra empoderamento tem sido muito utilizada na última década e passou a ser alvo de críticas, relacionadas sobretudo, ao conceito de poder, que pode remeter a dominação de um grupo sobre o outro. Neste texto, empoderamento é entendido em seu potencial coletivo, como apontado por Berth (2018) apenas o empoderamento individual não é o bastante, é imprescindível que isto esteja ligado ao coletivo e contribua para a luta de grupos e suas pautas. Não significa que as mulheres ao se empoderarem necessariamente precisam oprimir os homens, mas, sim, que a partir do momento em que se autoconhecem e se emancipam estão contribuindo para uma tomada de consciência coletiva e potencialização das reivindicações. Se empoderar não quer dizer que a pessoa deixa de sofrer às injustiças provocadas pelo meio social, ou seja, neste contexto, significa que ela passa a reconhecer essas discriminações e que pode atuar ativamente e criticamente no combate às mesmas.

\begin{tabular}{l|l|l}
\hline Unidades de Registro & \multicolumn{1}{c}{ Exemplos de Verbalizações } & \multicolumn{1}{c}{$\begin{array}{c}\text { Frequência } \\
\text { Relativa }\end{array}$} \\
\hline & $\begin{array}{l}\text { "Trajada com o que eu quiser" } \\
\text { "Luto pra minhas irmãs não serem a cada minuto assassinadas" } \\
\text { "Respeito mútuo pro rap feminino" } \\
\text { "Uma por todas e todas por uma vida" } \\
\text { "Quebrando barreira, seguindo adiante" } \\
\text { "Igualdade lutaremos até o fim!" } \\
\text { "No som várias minas representam e tem talento" } \\
\text { "Evoluo e construo" } \\
\text { "Rima antifa pró perifa, anti racismo ou transfobia" } \\
\text { "Sou guerreira no feminismo a militância" } \\
\text { "Sou negra e tenho orgulho da minha cor" } \\
\text { "Sou criança, sou negra também sou resistência" } \\
\text { "Delete nos machistas" } \\
\text { "A luta é nossa, persista, conquista, insista. Várias delas } \\
\text { destruindo essa droga sexista!" } \\
\text { "Todo lugar é meu lugar" } \\
\text { "Levantando a cabeça toda vez que eles nos disserem não" } \\
\text { "Preta no melhor lugar" } \\
\text { "Engole todo seu machismo e reconhece" } \\
\text { "Lugar de mulher é onde ela quiser!" } \\
\text { "Sou uma mulher de garra, preta de quebrada" } \\
\text { "Que eu nunca me cale" }\end{array}$ \\
\hline
\end{tabular}


"Ela é mais mais mais"

"Ela opera a festa, Ela é quem comanda"

"Não quer ser considerada símbolo sexual"

"Luta pra chegar ao poder, provar a sua moral"

"Exige direitos iguais"

"Temos de defender nossas verdadeiras guerreiras. Um viva às

mulheres brasileiras..."

"Devem se unir e derrubar essa ditadura do corpo perfeito"

\section{Metatexto}

A categoria "Empoderamento feminino" aponta que nos raps que possuem verbalizações a respeito do tema, são em sua maioria de mulheres, $93 \%$, e possuem menos frequência nos raps feitos por homens, $7 \%$.

A "UR1 - Mulheres" aponta para a necessidade de assunção da identidade da mulher e o incentivo à realização deste processo e sua importância. É destacado que a mulher deve ter liberdade para ser o que deseja, estar onde quer e se vestir da maneira que gosta, sem se preocupar com os julgamentos. A necessidade de união das mulheres é muito citada, sendo destacada sua importância para que se alcance mudanças mais significativas nas relações desiguais de gênero, raça e classe. As mulheres são incentivadas a ocuparem os setores da sociedade e mostrares suas potencialidades, exigindo reconhecimento. Todas as formas de preconceito e discriminação são rejeitadas, como o machismo, misoginia, racismo e transfobia, demonstrando que essas mulheres não lutam apenas por si próprias, mas também pelas outras minorias discriminadas. A mulher negra é bastante abordada, ressaltando que deve assumir sua identidade enquanto mulher e negra, que é linda da forma que é e que deve resistir a discriminações impostas. Assim, as mulheres são estimuladas a lutares, a não aceitarem ser diminuídas e a viverem do modo que desejarem.

O empoderamento feminino disseminado por homens, na "UR2 - Homens", ocorre de forma menos frequente, mas se assemelha em partes às verbalizações das mulheres em relação a exaltação da beleza e luta pela equidade. Os rappers destacam que as mulheres são guerreiras, lutam contra as desigualdades e objetificação, ressaltando a necessidade de empatia com suas reivindicações por direitos fundamentais e contribuição nesta. Há, ainda, verbalizações relacionadas a beleza das mulheres, que estas não devem aceitar padrões de beleza estabelecidos pela sociedade.

Portanto, a abordagem da temática do empoderamento ocorre com maior frequência nos raps de mulheres do que nos de homens. Apesar dos homens discutirem menos a temática, essas pequenas verbalizações já proporcionam alguns avanços, uma vez que as músicas masculinas dominam o cenário do Hip Hop e assim disseminam o assunto para as(os) ouvintes. $O$ fato das mulheres discutirem com muita frequência o empoderamento é importante pois, evidencia o quanto suas pautas são fundamentais no contexto de afirmação social, cultural e política, e à medida que as mulheres demonstram que possuem empatia por suas companheiras e que identificam as dificuldades que enfrentam cotidianamente, podem possibilitar que outras mulheres reconheçam situações machistas e de subordinação, passando a não considerar o fato como algo normal e se impor.

Org.: os autores, 2019.

A Tabela 4 evidencia que nos raps que citam mulheres, uma característica marcante é a denúncia das desigualdades de gênero proveniente tanto das rappers quanto dos rappers. Essa denúncia ressalta a função política do rap enquanto voz da periferia, ela proporciona que grupos que não se interessam pela temática ainda assim recebam informações acerca dela, tendo a chance de despertar sua curiosidade ou reconhecer situações que intensificam as disparidades de gênero.

Tabela 4: Denúncia das desigualdades de gênero

Categoria: Denúncia das desigualdades de gênero

As desigualdades de gênero se manifestam à medida que homens e mulheres tem acesso diferenciado e desigual a determinados recursos como os sociais, políticos, econômicos e culturais. As mulheres são vistas como inferiores aos homens e por este motivo são condicionadas pelas estruturas sociais a vivenciar diversas situações como diferença de tratamento, recebimento de salários menores pelo exercício da mesma função, estabelecimento de estereótipos, abusos sexuais e pouca representatividade em setores da sociedade. Portanto, esta categoria apresenta os trechos dos raps que denunciam essas injustiças de gênero que permeia a sociedade brasileira.

\begin{tabular}{l|l|c}
\hline Unidades de Registro & \multicolumn{1}{c}{ Exemplos de Verbalizações } & $\begin{array}{c}\text { Frequência } \\
\text { Relativa }\end{array}$ \\
\hline \multirow{2}{*}{ UR1 - Mulheres } & $\begin{array}{l}\text { "Prejudica nosso rolê os corre e proceder" } \\
\text { "Machismo atrasa nas ideia" } \\
\text { "Me oprime e me reprime e quer que eu cale a boca" } \\
\text { "Infelizmente o machismo continua tão presente" } \\
\text { "Sua gordofobia nojenta não sairá daqui isenta" } \\
\text { "Respeito e equidade de gênero não ta tendo" } \\
\text { "Diminuir a nossa luta Respeito é a primeira regra" } \\
\text { "Sentindo na pele o quanto é difícil. Ser mulher aqui é carregar o }\end{array}$ & $51 \%$ \\
\hline
\end{tabular}


peso de cem edifício"

"Homem privilegiado mais sistema, oprimia"

"Ninguém merece ser tirada de otária"

"Canto pela preta objetificada"

"Já sofreu o sistema na pele"

"Outra mulher estuprada. Com vinte e poucos anos.

Interromperam seus planos. Uma vida despedaçada. Eterno é o

trauma. Na alma violentada"

"Enquanto eu estou rimando. Outra mina é assassinada"

"O preço que se paga"

"Por ter nascido mulher"

UR2 - Homens

"Onde a mulher negra é dita como irresistível"

"A mulher negra é vista como incontratável"

"A cada 11 minutos, uma mulher é violentada"

"É a imagem feminina / É só um produto da mídia"

"Já se pensa que são apenas um produto sexual"

"Julgadas elas foram no passado, queimaram sutiãs. Foram

guerreiras, olhe para sua mãe e sua irmã"

"40 mil mulheres mortas entre 1997 e 2001 "

"A cada doze segundos, uma mulher é estuprada no Brasil, para

você ver"

\section{Metatexto}

No que diz respeito à categoria em questão, é perceptível que nos raps selecionados, tanto de homens como de mulheres, este debate é muito presente. De todos os trechos dos raps relacionadas ao tema, 51\% das verbalizações são de mulheres e $49 \%$ são de homens.

A "UR1 - Mulheres" demonstra que as verbalizações estão voltadas para o quão prejudicial as desigualdades de gênero são para elas. O machismo é muito citado e visto como forma de opressão e diminuição da mulher, além disso, as verbalizações apontam para o reconhecimento dos privilégios que os homens possuem o que contribui ainda mais para a estigmatização da mulher. Os raps denunciam também a objetificação da mulher, em especial da mulher negra, que é vista como sensual e objeto de desejo. As mulheres revelam que reconhecem as dificuldades que enfrentam cotidianamente, as tentativas de diminuição de sua luta e a falta de respeito com suas demandas.

A "UR2 - Homens" revela que nos raps que versam a respeito das mulheres, a denúncia das disparidades de gênero é muito frequente. Os rappers reconhecem a força das mulheres e as lutas que travam diariamente. A apropriação da imagem das mulheres e sua objetificação é citada, destacando que são vistas pela mídia como um produto a ser vendido que é irresistível, sensual e rentável. As dificuldades da mulher negra também são abordadas a partir da menção de que estas possuem remunerações menores e mais dificuldades para conseguir um emprego. Além disso, um tema muito citado é o abuso sexual contra as mulheres, os rappers apontam que muitas mulheres são estupradas, violentadas e mortas e que convivem cotidianamente com o medo de sofrer esses tipos de violências.

Desta forma, a acusação das injustiças de gênero está presente nos raps analisados e ocorre em frequência semelhante nos raps de homens e mulheres. As mulheres versam a respeito das barreiras enfrentadas em uma sociedade machista e ressaltam a força que possuem para romper esses obstáculos e alcançar uma maior equidade. Os elementos com maior presença nos raps masculinos são a violência contra a mulher e a objetificação da mesma, alguns homens demonstram reconhecer os privilégios que possuem e denunciam essas desigualdades. Nestes cenários, respeito é uma palavra essencial e muito citada nos raps.

Org.: os autores, 2019.

A Tabela 5 revela que enquanto muitos raps denunciam a objetificação das mulheres, há raps que reproduzem essa ação reforçando a imagem da mulher como submissa, objeto e símbolo sexual. Esse ato se manifesta com maior predominância entre os raps masculinos, apontando como o machismo está presente no rap, um movimento que deveria contribuir em sua totalidade para emancipação das mulheres, assim como faz com a grande maioria da população negra. Em relação às rappers, infelizmente, algumas ainda reproduzem discursos machistas e contribuem para a inferiorização das companheiras e até das próprias demandas das mulheres como um todo. Isso aponta para a necessidade dessas mulheres reconhecerem seus atos prejudiciais, reconhecerem seu poder de atingir a população por meio da música e mudarem suas posturas, não diminuindo outras mulheres. 
Tabela 5: Estigmatização da mulher

Categoria: Estigmatização da mulher

De acordo com Goffman (1981), a sociedade estabelece uma série de meios para categorizar pessoas de acordo com atributos considerados comuns e incomuns. Os atributos considerados comuns são transformados em expectativas e exigências para alguém se tornar aceita(o). Quando a pessoa não se encaixa nesses padrões, ela é vista como menos desejável, perigosa e é diminuída. Essas características se tornam, deste modo, estigmas à medida que são consideradas um defeito, fraqueza ou desvantagem.

$\mathrm{O}$ autor destaca a importância de transformar esses estigmas em normalidade: "O termo estigma, portanto, será usado em referência a um atributo profundamente depreciativo, mas o que é preciso, na realidade, é uma linguagem de relações e não de atributos. Um atributo que estigmatiza alguém pode confirmar a normalidade de outrem, portanto ele não é, em si mesmo, nem horroroso nem desonroso" (GOFFMAN, 1981, p. 6).

Portanto, nesta categoria, são apresentados os estigmas que perseguem as mulheres ao longo de suas vidas e de suas ações. Essa discussão se aproxima do termo estereótipo, que de acordo com Sant'Ana (2005) é um modelo preestabelecido por determinados sujeitos que consideram que devem ser seguidos por todas(os). Desta forma, são estabelecidos estereótipos em que as mulheres devem se adequar e quando isso não acontece, as mesmas são estigmatizadas por meio de palavras depreciativas.

\begin{tabular}{|c|c|c|}
\hline Unidades de Registro & Exemplos de Verbalizações & $\begin{array}{c}\text { Frequência } \\
\text { Relativa }\end{array}$ \\
\hline UR1 - Mulheres & $\begin{array}{l}\text { "Usar a bunda no lugar do cérebro, só quer viver disso" } \\
\text { "Rebolar pra ter ibope pra que nem preciso" } \\
\text { "Qual será o mais novo traseiro de sucesso" } \\
\text { "Manipulada mais desejada pela massa. No próprio espelho você } \\
\text { é a escrava" } \\
\text { "Acostumada com os halteres se impressiona com as pesada" }\end{array}$ & $9 \%$ \\
\hline UR2 - Homens & $\begin{array}{l}\text { "Maquiavélica me atraiu" } \\
\text { "Bundinha empinada pra mostrar que é bonita" } \\
\text { "Vocês são o mais puro retrato da falsidade" } \\
\text { "Mas eu prefiro mulher de verdade" } \\
\text { "Você é medíocre e ainda sim orgulhosa" } \\
\text { "Mulheres vulgares. Uma noite e nada mais" } \\
\text { "Mulheres só querem/preferem o que as favorecem, só pensa em } \\
\text { dinheiro, pra viver bem sossegada" } \\
\text { "Ou então aquela puta daquela panicat" } \\
\text { "Eu sei que existem mulheres que não prestam" } \\
\text { "Aceitam e se submetem ao jogo que as coloca como objeto" } \\
\text { "Mulher e dinheiro, dinheiro e mulher, quanto mais você tem } \\
\text { muito mais você quer, mesmo" } \\
\text { "Mulher finge bem, casar é negócio" } \\
\text { "Parece que ela tem parentesco com satanás" } \\
\text { "Eu quero paz, buceta não falta" }\end{array}$ & $91 \%$ \\
\hline
\end{tabular}

\section{Metatexto}

Nesta categoria relacionada a estigmatização ou objetificação das mulheres, nota-se que a maior parte dos raps que são classificados nesta temática são cantados por homens, $91 \%$, e a minoria é cantado por mulheres, $9 \%$. Ao contrário do que se pensa, muitas mulheres apesar de possuírem um senso de criticidade, ainda acreditam que determinadas mulheres não agregam nada à sua luta e assim diminuem as companheiras, isso reflete como o sistema de dominação masculina está arraigado na sociedade e faz com que mulheres reproduzam diversas falas sexistas.

Sendo o rap uma linguagem que possibilita denunciar as desigualdades e reivindicar demandas, é importante que as mulheres aceitem as companheiras em suas lutas e não as discriminem, porém, por meio da "UR1 - Mulheres" nota-se que muitas rappers reproduzem estigmas que são disseminados na sociedade. Elas destacam as características femininas consideradas negativas e reforçam os estereótipos. Nas músicas que versavam essas verbalizações, as mulheres classificavam outras como algo errado e afirmavam sua diferença em relação a elas, acreditando que não contribuíam para a luta, apenas para diminuição desta. Características ligadas à sua aparência são ressaltadas, como as roupas que usam e seus gestos, nota-se que são vistas como superficiais e que se importam apenas com sua imagem.

A "UR2 - Homens" aponta os tipos de verbalizações que raps feitos por homens utilizam e são identificados como uma estigmatização da mulher. Nestas músicas a mulher é vista como um objeto que está a serviço do homem nos momentos que ele desejar e como alguém superficial que se interessa apenas pelo dinheiro e age sempre em busca de benefícios, sendo até mesmo vista como falsa e fingida. Um aspecto muito presente é a retratação das mulheres nos relacionamentos, elas são representadas como traidoras e ruins, que destruíram com a vida do homem e estavam no relacionamento apenas por interesse.

Deste modo, os raps que se enquadram na estigmatização da mulher demonstram ser o reflexo das opiniões conservadoras disseminadas na sociedade atual diariamente, em que a mulher é vista como submissa ao homem e que escolhe seus companheiros de acordo com os bens que os mesmos possuem. Um fator alarmante é que não 
apenas rappers homens, mas também rappers mulheres reproduzem esses discursos. Essas rappers fazem parte de um movimento que tem sua gênese na crítica das desigualdades e demonstram não reconhecer isso, ou se reconhecem deixam explícito que muitas mulheres ainda assim não merecem respeito por serem superficiais, as verbalizações neste sentido demonstram a falta de consciência de classe, raça e gênero. No que diz respeito aos homens, é essencial uma sensibilização dos rappers frente às dificuldades enfrentadas pelas mulheres, eles possuem grande visibilidade no cenário do rap e à medida que reproduzem discursos machistas, discriminatórios e opressores enfraquecem a luta das mulheres por equidade.

Org.: os autores.

Faz-se pertinente compreender como estas categorias e as unidades de registros se materializam no universo total de verbalizações, assim, a frequência absoluta dos trechos também foi analisada, conforme se expõem na Tabela 6.

Tabela 6: Frequência absoluta das verbalizações a respeito das mulheres

\begin{tabular}{ccc}
\hline Categoria / Ur & Mulheres & Homens \\
\hline Empoderamento feminino & $29 \%$ & $9 \%$ \\
Denúncia das desigualdades de gênero & $20 \%$ & $15 \%$ \\
Estigmatização da mulher & $8 \%$ & $19 \%$ \\
\hline
\end{tabular}

Org.: os autores.

De acordo com a Tabela 6, do total de verbalizações a maioria eram acerca do empoderamento feminino e cantadas por mulheres (29\%) e na sequência o tema mais citado foi a desigualdade de gênero também discutido por mulheres (20\%). Um dado que chama a atenção é que os raps selecionados cantados por homens versam em sua maioria a respeito da estigmatização da mulher (19\%). A minoria dos raps femininos são relacionados a objetificação, fato positivo que aponta para uma criticidade das mulheres em relação aos contextos que as companheiras vivenciam.

Uma característica pertinente e que pode auxiliar na compreensão da forma como as mulheres são retratadas nos raps em questão, é o ano de produção das músicas. Os raps femininos se concentram entre os anos de 2015 a 2018, com maior expressividade dos anos de 2016 e 2017, sendo que nesse período as discussões de gênero eram mais disseminadas, podendo ser essa uma das razões pela maior politização das músicas de mulheres, além de outros fatores já discutidos, como a própria vivência de contextos de subordinação das rappers. Em relação aos homens, os raps abrangem um período maior do ano de 1990 a 2017. Uma das músicas que mais sexualiza e inferioza as mulheres é "Mulheres vulgares" dos Racionais MC's de 1990, nessa década o debate de gênero não era ampliado para diversas esferas da sociedade, principalmente na cultura Hip Hop, e o contexto geográfico dos cantores os condicionava a uma série de pensamentos machistas que era refletido em suas composições. É importante destacar que não estamos encontrando uma justificativa para diminuir o impacto de raps que estigmatizam as mulheres, mas, sim, que estamos evidenciando como o contexto histórico e geográfico em que foram produzidos, influência nos versos.

De um modo geral, é perceptível que os raps masculinos que citam mulheres discutem o empoderamento feminino - ainda que com pouca frequência - e são muito significativos no que diz respeito a denúncia das desigualdades de gênero, porém, as verbalizações predominantes são oriundas de discursos que estigmatizam as mulheres. Esse cenário indica a urgência de raps masculinos que reconheçam as dificuldades enfrentadas pelas mulheres e que não as sexualizem. Os homens possuem mais visibilidade que as mulheres na cena do Hip Hop nacional e é preciso que realizem discussões críticas relacionadas ao gênero, uma vez que à medida que mais discursos de objetificação forem produzidos mais eles serão reproduzidos pelas(os) ouvintes.

Em relação aos raps femininos a questão do empoderamento da mulher e da denúncia das diferenças de gênero são as mais presentes, contribuindo para o enfrentamento das relações de inferiorização, porém, ainda existem mulheres - em menor quantidade - que reproduzem discursos machistas ao diferenciar as que consideram sérias das que rotulam apenas como objeto, como já dito, isso reflete o contexto de dominação masculina em que foram criadas, apontado para a importância da problematização das relações de gênero.

Tendo em vista o alcance nacional do rap, se faz fundamental que os rappers e as rappers compreendam a dimensão de seu trabalho que é divulgado nos diversos lugares do Brasil e utilizem esse elemento como potencializador da sua luta por equidade, não reproduzindo discursos discriminatórios. 
Portanto, por meio da análise se evidencia que as mulheres têm ocupado espaços no rap e estão quebrando barreiras impostas a elas historicamente em diversos âmbitos da sociedade, inclusive no Hip Hop e até mesmo no rap. Por meio das músicas analisadas, as mulheres estão utilizando o rap a seu favor e mediante a fala denunciam as situações de discriminação disseminam discursos de afirmação e empatia que possibilitam que outras mulheres se identifiquem com o elemento e se sintam representadas de forma justa. Muitos rappers também têm contribuído para a afirmação das mulheres e sua ocupação dos espaços, porém esse processo ocorre simultâneo a raps que estigmatizam as mulheres, apontando para a necessidade de maior politização dos homens no que diz respeito às relações de gênero.

\section{Considerações finais}

A materialização das mulheres nos diversos âmbitos da sociedade é fundamental, a partir disso elas modificam o espaço geográfico e mostram que também possuem direito a ocuparem os locais, inspirando outras mulheres e as incentivando a participarem da luta pela equidade. No caso do Hip Hop, a cultura, enquanto forma de denúncia às realidades marcadas por problemas sociais, econômicos e políticos, oferece às mulheres elementos que podem auxiliar na reivindicação de suas pautas, por meio do rap, grafite e dança.

O cenário abordado para a pesquisa foi o rap, por meio da análise de músicas produzidas por homens e mulheres, se evidenciou como essas últimas são representadas. Essa ação importa à medida que o rap possui um alcance nacional e se faz importante que o conteúdo de suas letras seja politizado e não estigmatize nenhum tipo de grupo social. A partir da presença das mulheres nessa cena elas podem expor suas demandas e ocupar um espaço composto, sobretudo, por homens.

Por meio da análise dos raps produzidos por homens e por mulheres é possível afirmar que os rappers discutem as desigualdades de gênero e apontam situações vivenciadas pelas mulheres, em contrapartida o empoderamento feminino é abordado com pouca frequência e uma significativa parte das verbalizações em suas rimas reproduzem discursos que estigmatizam as mulheres. Já em relação aos raps produzidos por mulheres, a característica principal é a predominância da discussão do empoderamento feminino e das diferenças de gênero, porém ainda assim há a reprodução de alguns discursos machistas.

O movimento Hip Hop e o rap ainda são compostos predominantemente por homens e os conteúdos de diversas rimas reforçam os discursos machistas e que objetificam as mulheres. Faz-se necessário que os rappers percebam que possuem uma grande visibilidade no cenário do rap e que por meio de sua denúncia das discrepâncias raciais e de gênero, as pautas femininas podem ganhar mais força. $O$ rap representa a voz da periferia e a presença e participação de mulheres em suas manifestações, assim como outros grupos sociais vulneráveis, é extremamente empoderador e possibilita a divulgação da realidade vivenciada por elas cotidianamente.

O espaço geográfico enquanto produto de interrelações reflete os convívios sociais, deste modo, os espaços que conhecemos atualmente foram pensados por e para homens. Aos grupos subordinados historicamente foram destinados os espaços marginais. Desta forma, aponta-se para a importância de que os mesmos assumam papel de produção ativa de seus contextos geográficos. As mulheres fazem parte desses grupos, elas são obrigadas a instituir espacialidades secundárias e restritas a determinadas áreas das cidades, como por exemplo, os trajetos resumidos à casa e ao trabalho. Deste modo, a partir da participação em determinadas atividades, como as culturas, neste caso em especial o Hip Hop, as mulheres têm acesso a uma forma de lazer que se soma ao combate às assimetrias de gênero, coexistindo com as(os) diferentes, ocupando espaços distintos do habitual, imprimindo suas identidades e tornando-os mais democráticos.

Por meio do rap as mulheres podem mudar suas realidades espaciais, primeiramente elas ocupam os espaços da cultura em questão e divulgam suas vivências para as(os) praticantes. E em uma escala mais ampla, por meio das divulgações das músicas além dos espaços periféricos - cenário em que o Hip Hop possui mais força -, as rappers podem expor suas pautas para pessoas que desconhecem os espaços em que elas vivem e ocupar os que não foram destinados a elas, como as mídias e as instituições culturais. Daí a necessidade de que os raps sejam politizados e não disseminem estereótipos.

Com base na participação em uma cultura e na união entre as companheiras que fazem parte da mesma, as mulheres passam a possuir circuitos mais amplos, mobilidades mais significativas que não se restringem apenas as periferias, mas também ao centro e aos espaços que sejam públicos ou privados.

Por fim, uma vez que os raps analisados possuem grande ênfase na denúncia das desigualdades de gênero e no empoderamento feminino, eles contribuem para que as demandas sejam divulgadas e a exclusão sócioespacial seja, em certa medida, combatida, ampliando as escalas de ações. Porém, ainda há raps que sexualizam as mulheres, sendo, portanto, fundamental que as músicas rompam com as ideias machistas, de 
modo que o público que consome esse produto não seja "incentivado" a reproduzi-las nas relações sociais que estabelecem e em seus contextos geográficos.

\section{Referências}

ADICHIE, C. N. Sejamos todos feministas. 1 ed. São Paulo: Companhia das Letras, 2014.

BARDIN, L. L'analyse de contenu. 8 ed. Paris: Presses Universitaires de France, 1977.

BEAUVOIR, S. O segundo sexo: a experiência vivida. 2 ed. São Paulo: Difusão Europeia do Livro, 1967.

BEAUVOIR, S. O segundo sexo: fatos e mitos. 4 ed. São Paulo: Difusão Europeia do Livro, 1970.

BERTH, J. O que é empoderamento? 1 ed. Belo Horizonte: Letramento/Justificando, 2018.

BUTLER, J. Problemas de gênero: feminismo e subversão da identidade. 1 ed. Rio de Janeiro: Civilização Brasileira, 2003.

CARNEIRO, S. Mulheres em movimento. Estudos avançados. v. 17, n. 49, p. 117-132, 2003 a.

CARNEIRO, S. Enegrecer o feminismo: a situação da mulher negra na América Latina a partir de uma perspectiva de gênero. In: ASAKA Empreendedores sociais; TAKANO Cidadania (Orgs.). Racismos contemporâneos. Rio de Janeiro: Takano Editora, 2003b.

CRENSHAW, K. W. A intersecionalidade na discriminação de raça e gênero. In: Cruzamento: raça e gênero. Brasília: Unifem, 2004, p. 7-16.

FONSECA, R. L. Avaliação da preparação de graduandos de Geografia para a inclusão de alunos com necessidades educacionais especiais. 2015. 183 f. Tese (Doutorado em Geografia) - Universidade Estadual de Londrina, Londrina, 2015.

GOFFMAN, E. Estigma: notas sobre a manipulação da identidade deteriorada. 4 ed. São Paulo: LTC, 1981.

IBGE, INSTITUTO BRASILEIRO DE GEOGRAFIA E ESTATÍSTICA. Estatísticas de Gênero: Indicadores sociais das mulheres no Brasil. 2018. Disponível em: $<$ https://agenciadenoticias.ibge.gov.br/media/com_mediaibge/arquivos/9d6f4faeda1f1fb7532be7a9240cc233 .pdf $>$.

MASSEY, D. B. Pelo espaço: uma nova política da espacialidade. Rio de Janeiro: Bertrand Brasil, 2008.

MATSUNAGA, P. S. As representações sociais da mulher no movimento Hip Hop. Psicologia \& Sociedade. v. 20, n. 1, 108-116, 2008.

DOI: $10.1590 / \mathrm{S} 0102-71822008000100012$.

MONK, J.; HANSON, S. Não excluam metade da humanidade da geografia humana. In: SILVA, J. M.; ORNAT, M. J.; CHIMIN JUNIOR, A. B. (orgs). Geografias feministas e das sexualidades: encontros e diferenças. 1 ed. Ponta Grossa: Todapalavra, 2016, p. 31-54.

RUBIN, G. O tráfico de mulheres: notas sobre a "economia política" do sexo. Tradução de Jamile Pinheiro Dias. São Paulo, Ubu Editora, 2017.

SALVI, R. F. A importância da compreensão da circularidade que envolve o processo metodológico da pesquisa qualitativa. In: BATISTA, I. L.; SALVI, R. F. (orgs). Pós-Graduação em Ensino de Ciências e Educação Matemática (um perfil de pesquisas). 1 ed. Londrina: EDUEL, 2009. p. 167-181.

SANT' ANA, A. O. e. História e Conceitos Básicos sobre o Racismo e seus Derivados. In: MUNANGA, K. (org). Superando o Racismo na escola. 2. ed. Brasília: Ministério da Educação, Secretária de Educação Continuada, Alfabetização e Diversidade, 2005. p. 39-67. 
SILVA, J. M. Fazendo geografias: pluriversalidades sobre gênero e sexualidades. In: SILVA, J. M. (org.). Geografias subversivas: discurso sobre espaço, gênero e sexualidades. 1 ed. Ponta Grossa: Todapalavra, 2009a. p. 25-54.

SILVA, J. M.. Geografias feministas, sexualidades e corporalidades: desafios às práticas investigativas da ciência geográfica. In: SILVA, J. M. (org.). Geografias subversivas: discurso sobre espaço, gênero e sexualidades. 1 ed. Ponta Grossa: Todapalavra, 2009b. p. 93-114. 